\title{
Radiotherapy for Benign Diseases
}

\author{
Jha AK,' Prasiko G, ${ }^{1}$ Mod H, ' Chaurasia PP,' Srivastava R' \\ 'Department of Radiation Oncology, BP Koirala Memorial Cancer Hospital, Bharatpur, Chitwan
}

\section{ABSTRACT}

Radiotherapy mainly involves treatment of patients with malignant tumors. Even with recognition of the risks of late skin injury, carcinogenesis, leukemogenesis, and genetic damage from all ionizing radiation; radiation therapy also continues to be accepted treatment for benign diseases.

Before initiation, the quality of irradiation, total dose, overall time, underlying organs at risk, and shielding factors should be considered. Children should be treated with ionizing radiation only in very exceptional cases and after weighing the pros and cons of the therapy. Direct irradiation of skin areas overlying organs that are particularly prone to late effects (e.g. thyroid, eye, gonads, bone marrow and breast) should be avoided. Radiation protection techniques should be used in all instances. The depth of penetration of the x-ray beam should be chosen according to the depth of the pathologic process. Choice of beam energy usually depends on the depth of the target volume; every effort is made to spare normal underlying tissue in superficial lesions.

There are a number of other benign conditions that can be treated with radiotherapy; we present a brief overview of some of the commonly encountered conditions.

Key Words: benign diseases, dose, keloids, radiation therapy, radiation protection, recurrence

\section{INTRODUCTION}

Radiation therapy is a clinical modality dealing with the use of ionizing radiations in the treatment of patients with malignant neoplasias. Treatment with ionizing radiation involves the risks of late skin damage, genetic damage and radiation-induced carcinogenesis. After weighing the pros and cons of the treatment; radiation therapy also is accepted for treatment of certain benign diseases. $^{1}$
Certain factors like the quality of irradiation, total dose, overall treatment time, underlying organs at risk, and shielding factors should be taken into account before starting the treatment. Children should be treated only in very exceptional cases and after considering the benefits versus the risks of the treatment. Certain underlying organs like thyroid, eye, gonads, bone marrow, and breast are especially prone to late effects of radiation therapy and therefore direct irradiation of the skin overlying these structures should be avoided.

\footnotetext{
Correspondence:

Dr. Anjani Kumar Jha

Department of Radiation Oncology

BP Koirala Memorial Cancer Hospital, Bharatpur, Chitwan

Phone: +977-9845064209

E-mail: anjani@operamail.com
} 
Jha et al. Radiotherapy for Benign Diseases

Radiation protection techniques to spare the adjacent normal structures/ organs should be used as and when feasible as the aim of radiation therapy is to deliver a precisely measured dose of irradiation to a defined volume with as minimal damage as possible to surrounding healthy tissue, resulting in eradication of the tumor, a high quality of life, and prolongation of survival at competitive cost.

The energy of the $\mathrm{x}$-ray beam and depth of penetration are chosen according to the depth of the disease and every effort is made to spare normal underlying tissue in cases where treatment involves superficial lesions.

\section{SKIN}

\section{A. Keloids}

Excessive production of fibrous tissue that extends beyond the wound, becomes hyalinized and does not regress spontaneously is a keloid. The recurrence rate after excision is very high and surgical treatment alone is not recommended. ${ }^{2}$

The preferred treatment is excision followed by a method to prevent fibroblast proliferation leading to recurrence. Although good results have been reported with local injections of triamcinolone, postoperative radiation therapy is effective and is more comfortable for patients. ${ }^{3-5}$ Radiation therapy is usually started within 24 hours after excision; the total dose is 10 to $15 \mathrm{~Gy}$ in two to five fractions in one to two weeks. Most recurrences occur within one year and a minimum follow-up of two years is recommended. ${ }^{6}$

\section{B. Plantar Warts}

Radiation treatment for plantar warts is simple, safe, and effective. The wart usually separates and falls off in three to four weeks. ${ }^{7}$

\section{Keratoacanthoma}

Keratoacanthoma is a rapidly growing benign tumor that may be locally invasive. Complete excision with adequate margins is the treatment of choice. ${ }^{8-10}$ Radiation therapy is recommended for recurrences after surgery or when surgery results in poor cosmesis. The doses range from $35 \mathrm{~Gy}$ in 15 fractions to $56 \mathrm{~Gy}$ in 28 fractions. ${ }^{11}$

\section{EYE}

\section{A. Pterygium}

The treatment of pterygium is surgical, but the recurrence rate is $20 \%$ to $30 \%$ without further treatment. ${ }^{12}$ Local control is significantly improved when beta-irradiation with strontium $(\mathrm{Sr} 90)$ plaques is administered immediately after surgery. ${ }^{13}$ The dose is 8$10 \mathrm{~Gy}$ in each fraction for three fractions each week.

\section{B. Exophthalmos}

The pathogenesis is believed to be an autoimmune disease in which activated T-lymphocytes invade the orbit resulting in tissue edema, lymphocytic infiltration, and marked enlargement of the extraocular muscles. Because lymphocytes and fibroblasts are sensitive to radiation, retrobulbar irradiation is a logical method of treatment. Systemic high-dose steroids are customarily used, but they must be given for long periods and have many side effects. Surgical orbital decompression can be considered when there is rapidly progressive optic neuropathy or severe proptosis. The total dose is 20 Gy to the midplane, given in 10 fractions over two weeks. ${ }^{14,15}$

\section{Orbital Pseudotumor}

Radiation therapy is effective, although corticosteroids are usually administered first 4 to $6-\mathrm{MV}$ photon beam is used with unilateral or bilateral temporal fields sparing the lens. ${ }^{16}$ The usual dose is $20 \mathrm{~Gy}$ in 10 fractions over 2-weeks. ${ }^{17-19}$ Patients must be monitored closely, because subsequent progression to systemic lymphoma is reported in up to $30 \%$ of patients. ${ }^{20-22}$

\section{HEMANGIOMAS}

\section{A. Cutaneous Lesions}

A trial of oral steroids is now the preferred treatment for skin hemangiomas requiring intervention. Radiation therapy is reserved for lesions that endanger function or life and have failed other therapies. ${ }^{23}$ The skin dose is 5 to $10 \mathrm{~Gy}$ per treatment. ${ }^{24}$

\section{B. Cavernous Hemangiomas of the Liver}

Radiation therapy has been used for symptomatic and unresectable lesions. The usual doses are $10 \mathrm{~Gy}$ or less for children and 20 to $30 \mathrm{~Gy}$ in three to four weeks for adults. ${ }^{25}$ If no response is observed in four to six months, an additional 10 to $15 \mathrm{~Gy}$ in one to two weeks can be repeated. ${ }^{26}$

\section{Vertebral Hemangiomas}

Expansion of the vertebrae, extension of the tumor into the extradural space, hemorrhage or the rare compression fracture may lead to cord compression. Surgical decompression may be required but is usually difficult because of hemorrhage. Most often only limited surgery is possible and postoperative irradiation is recommended. ${ }^{27}$ Radiation therapy without surgical decompression has produced good results. The recommended dose is 30 to $40 \mathrm{~Gy}$ in four to six weeks. 
Jha et al. Radiotherapy for Benign Diseases

\section{CENTRAL NERVOUS SYSTEM}

\section{A. Arteriovenous malformations (AVMs)}

Stereo-tactic Radio surgery delivers a single fraction of high-dose irradiation to a small volume leading to sclerosis of the AVM and prevents hemorrhage. Minimum doses of 15 to $30 \mathrm{~Gy}$ are prescribed to the periphery of the target, and complete obliteration of the AVM is seen in $71 \%$ to $89 \%$ within two years. ${ }^{28-31}$

\section{B. Other benign brain tumours treated with radiation therapy}

Meningioma - It arises from the arachonoid meninges of the brain and grow at a slow rate. ${ }^{32}$ After initial surgery the average interval to recurrence is approximately four years. ${ }^{33-36}$ The treatment of choice is surgical resection if difficult, subtotal resection followed by post-op radiation gives good local control. ${ }^{37-40}$ Radiation dose is 50-54Gy in 25-30fractions over five to six weeks.

Pituitary Adenoma - Radiotherapy is indicated if surgical resection is not possible or if hormone level remains elevated following surgery. Dose of radiation is 45 to $50 \mathrm{~Gy}$ over five to six weeks.

Craniopharyngioma - It arise in the sellar region from remnants of rathke's pouch. External beam radiotherapy will be treatment of choice for patients with residual disease following surgery who are at high risk for progressive disease. ${ }^{41,42}$ Dose of radiation is $54 \mathrm{~Gy}$ in 30 fractions over 6 weeks. ${ }^{43-45}$

\section{SOFT TISSUES}

\section{A. Desmoid Tumors}

Also known as aggressive fibromatosis, are low-grade, locally invasive, nonmetastasizing tumors. These tumors are deeply infiltrative, nonencapsulated and merge into the surrounding muscle, resulting in positive margins after resection. Surgical resection is the treatment of choice, but local recurrence can occur in $10 \%$ to $100 \%$ depending on the extent of the surgical resection. Recurrences are usually effectively salvaged with further surgical resection or postoperative irradiation. ${ }^{46}$ If the lesion is inoperable because of location or infiltration of vital structures, surgery is not recommended and radiation therapy is effective. The recommended dose is 50 to $60 \mathrm{~Gy}$ in six to seven weeks at 1.8 to $2 \mathrm{~Gy}$ per fraction.

\section{B. Peyronie's Disease}

It is painful angulation of the erect penis. Although the disease resolves spontaneously over time, treatment with radiation is effective and hastens regression of symptoms, especially pain. Local corticosteroid injections, systemic corticosteroids, procarbazine, or surgery are also effective in relieving symptoms to varying extent. Effective doses range from $5 \mathrm{~Gy}$ in one fraction (which may be repeated in one month), to $3 \mathrm{~Gy}$ daily for six or seven fractions. ${ }^{47}$

\section{BONE}

\section{A. Ameloblastoma}

Ameloblastomas usually occur in the jaw, and rarely metastasize. Treatment is usually by curettage, but recurrence is common. Many patients have tumors that cannot be completely excised or may be inoperable. These lesions respond well to irradiation, and doses of 50 to $60 \mathrm{~Gy}$ in five to six weeks produce complete regression. ${ }^{48}$ Patients should be monitored closely, because tumor regression after irradiation proceeds slowly and late metastases may occur.

\section{B. Aneurysmal Bone Cysts}

Treatment is primarily surgical. Recurrence rates after curettage only are as high as $30 \%$ to $60 \%$. Radiation therapy is reserved for patients whose lesions are surgically inaccessible, difficult to curette properly, or continue to grow or repeatedly recur. Cysts of the spine and pelvis are especially suitable for irradiation. ${ }^{49}$ The usual recommended doses are in the range of 12 to 32 Gy at 2 Gy per fraction over two to three weeks.

\section{GLANDULAR TISSUE}

\section{A. Gynecomastia}

Gynecomastia may be seen in: patients receiving estrogens or flutamide, patients undergoing orchiectomy, being treated with luteinizing hormone-releasing hormone (LHRH) agonists, and in those receiving a combination of flutamide and LHRH agonists. ${ }^{50}$ In patients treated with estrogen, breast irradiation given before administration of estrogen is effective in preventing gynecomastia; irradiation is not effective if estrogen is given first. $9 \mathrm{~Gy}$ is given as a single dose or 4 to 5 Gy daily for three treatments. ${ }^{51}$ In addition to prophylactic treatment, radiation can be given for painful gynecomastia after diethylstilbestrol therapy with $20 \mathrm{~Gy}$ in 5 fractions or $40 \mathrm{~Gy}$ in 20 fractions. ${ }^{52}$ Pain relief is obtained after two weeks to 14 months, with an average of 3.6 months.

\section{B. Ovarian Castration}

Pelvic irradiation is used to induce ovarian ablation. The recommended dose is $20 \mathrm{~Gy}$ in 5 to 10 fractions. ${ }^{53}$

Total Lymphoid Irradiation in the Management of Autoimmune Diseases and Organ Transplantation 
Jha et al. Radiotherapy for Benign Diseases

Total lymphoid irradiation (TLI), is a curative form of treatment for early-stage Hodgkin's disease. TLI, usually in conjunction with other immunosuppressive therapies, promotes transplantation tolerance for bone marrow, skin, heart, and kidney grafts and decreases pharmacological immunosuppression after TLI. ${ }^{54}$ Radiation is given to mantle and inverted- $Y /$ spleen fields concurrently, using $0.8-\mathrm{Gy}$ fractions, two fractions per week, to a maximum total dose of $8 \mathrm{~Gy}$.

\section{CONCLUSION}

In addition to treatment of malignant diseases, radiation therapy can also be used for successful treatment of benign or non-malignant conditions either primarily or following surgery or when other modalities fail.

\section{REFERENCES}

1. Bureau of Radiological Health: A Review of the Use of Ionizing Radiation for the Treatment of Benign Disease; vol 1. Rockville, MD: USDepartment of Health, Education and Welfare; 1977. p. 1-2.

2. Converse JM: Reconstructive Plastic Surgery. Philadelphia: WB Saunders; 1968. p. 175

3. Borok TL, Bray M, Silclair I, et al: Role of ionization irradiation for 393 keloids. Int J Radiat Oncol Biol Phys 1988;15:865.

4. Griffith BH, Monroe CW, McKinney P: A follow-up study on the treatment of keloids with triamcinolone acetonide. Plast Reconstr Surg 46;145:1970.

5. Inalsingh $\mathrm{CH}$ : An experience in treating 501 patients with keloids. Johns Hopkins Med J 134;284:1974.

6. Kovalic JJ, Perez CA. Radiation therapy following keloidectomy: A 20-year experience. Int J Radiat Oncol Biol Phys 1989;17:77.

7. Hawley SJ. Roentgen therapy in some nonmalignant conditions. Radiology 59;225:1952.

8. Goldschmidt H, Sherwin WK: Radiation therapy of giant aggressive keratoacanthomas. Arch Dermatol 1993;129:1162.

9. Schwartz RA. Keratoacanthoma. J Am Acad Dermatol 30;1:1994.

10. Warner DM, Flowers F, Ramos-Caro FA. Solitary keratoacanthoma (squamous cell carcinoma):Surgical management. Int J Dermatol 34;17:1995.

11. Donahue B, Cooper JS, Rush S. Treatment of aggressive keratoacanthomas by radiotherapy. J Am Acad Dermatol 1990;23:489.

12. Cameron ME. Pterygium Throughout the World. Springfield, IL, Charles C Thomas, 1965.

13. Wilder RB, Buatti JM, Kittelson JM, et al. Pterygium treated with excision and postoperative beta irradiation. Int J Radiat Oncol Biol Phys 1992;23:533.

14. Burch HB, Wartofsky L. Graves' ophthalmopathy: Current concepts regarding pathogenesis and management. Endocr Rev 1993;14:747.

15. Petersen IA, Kriss JP, McDougall, et al. Prognostic factors in the radiotherapy of Graves' ophthalmopathy. Int J Radiat Oncol Biol Phys 19;259:1990.

16. Lanciano R, Fowble B, Sergott RC, et al. The results of radiotherapy for orbital pseudotumor. Int J Radiat Oncol Biol Phys 1990;8:407.
17. Austin-Seymour MM, Donaldson SS, Egbert PR, et al. Radiotherapy of lymphoid diseases of the orbit. Int J Radiat Oncol Biol Phys 11;371:1985.

18. Barthold HJ, Harvey A, Markoe AM, et al. Treatment of orbital pseudotumors and lymphoma. Am J Clin Oncol 9;527:1986.

19. Lanciano R, Fowble B, Sergott RC, et al. The results of radiotherapy for orbital pseudotumor. Int J Radiat Oncol Biol Phys 18;407:1990.

20. Keleti D, Flickinger JC, Hobson SR, et al. Radiotherapy of lymphoproliferative diseases of the orbit. Am J Clin Oncol 15;422:1992.

21. Knowles DM, Jakobiec FA. Orbital lymphoid neoplasms. Cancer 46:576, 1980

22. Lanciano R, Fowble B, Sergott RC, et al. The results of radiotherapy for orbital pseudotumor. Int J Radiat Oncol Biol Phys 18;407:1990.

23. Dutton SC, Plowman PN. Paediatric haemangiomas: The role of radiotherapy. Br J Radiol 1991;64:261.

24. Furst CJ, Lundell M, Holm LE. Radiation therapy of hemangiomas 1909-1959: A cohort based on 50 years of clinical practice at Radiumhemmet Stockholm. Acta Oncol 26;33:1987.

25. Gaspar L, Mascarenhas F, da Costa MS, et al. Radiation therapy in the unresectable cavernous hemangioma of the liver. Radiother Oncol 1993;29:45.

26. Gaspar L, Mascarenhas F, da Costa MS, et al: Radiation therapy in the unresectable cavernous hemangioma of the liver. Radiother Oncol 29;45:1993.

27. Yang ZY, Zhang LJ, Chen ZX, et al. Hemangioma of the vertebral column: A report on 23 patients with special reference to functionalrecovery after radiation therapy. Acta Radiol 1985;24:129.

28. Colombo F, Pozza F, Chierego G, et al. Linear accelerator radiosurgery for cerebral arteriovenous malformations: An update. Neurosurgery 1994;34:14.

29. Friedman W, Bova F, Mendenhall W. Linear accelerator radiosurgery for arteriovenous malformations: The relationship of size to outcome. J Neurosurg 82;180:1995.

30. Kondziolka D, Lunsford LD, Flickinger JC. Gamma knife stereotactic radiosurgery for cerebral vascular malformations. In Lunsford LD, editor. Stereotactic Radiosurgery. New York: McGraw-Hill; 1993. 
31. Steiner L, Lindquist C, Adler JR, et al. Clinical outcome of radiosurgery for cerebral arteriovenous malformations. J Neurosurg 77;1:1992.

32. QuestDO. Meningiomas:an update. Neurosurgery 1978;3:219225.

33. King DL, Chang $\mathrm{CH}$, pool JL. Radiotherapy in the management of meningiomas. Acta Radiol Ther Phys Biol 1966;5:26-33.

34. Melamed SH, Sahar A, Bellar AJ. The recurrence of intracranial meningiomas. Neurochirurgia (Stuttg) 1979;22:45-51.

35. Petty AM, Kun LE, Meyer GA. Radiation Therapy for incompletely resected meningiomas. J Neurosurg 1985;62:502507.

36. Taylor BW, Marcus RB Jr, Friedman WA, et al. The meningioma controversy: postoperative radiation theray. Int J Radiat Oncol Biol Phys 1988;15:299-304.

37. Acker JC, Bossen EH, Halperin EC: The management of desmoid tumors. Int J Radiat Oncol Biol Phys 26;851:993.

38. Condado JA, Wakman R, Gurdiel O, et al. Long-term angiographic and clinical outcome after percuntaneous transluminal coronary angioplasty and intracoronary radiation therapy in humans. Circulation 1997;96:727-732.

39. Trentham DE, Belli JA, Anderson RJ, et al: Clinical and immunological effects of fractionated total lymphoid irradiation refractory rheumatoid arthritis. N Engl J Med 305;976:1981.

40. Barbaro NM, Gutin PH, Wilson CB, et al. Radiation Therapy in the treatment of partially resected meningiomas. Neurosurgery 1987;20:525-528.

41. Fahlbusch R, Honneger J, Paulus W, et al. Surgical treatment of craniopharyngiomas: experience with 168 patients. J Neurosurg 1990;72:572-582.

42. Fisher PG, Jenab J, Goldthwaite PT, et al. Outcomes and failure patterns in childhood craniopharyngiomas. Childs Nerv Syst 1998;14:558-563.

43. Rajan B, Ashley S, Gorman C, et al. Craniopharyngioma-long term results following limited surgery and radiotherapy. Radiother Oncol 1993;26:1-10.
44. Rajan B, Ashley S, Thomas DGT, et al. Craniopharyngioma : improving outcome by early recognition of acute complications. Int J Radiat Oncol Biol Phys 1997;37:517-521.

45. Scott RM, Hetelekidis S, Barnes PD, et al. Surgery, radiation and combination therapy in the treatment of childhood craniopharyngioma - a 20 year experience. Pediatr Neurosurg 1994;21(Suppl 1):75-81.

46. Acker JC, Bossen EH, Halperin EC: The management of desmoid tumors. Int J Radiat Oncol Biol Phys 1993;26:851.

47. Rodrigues CI, Hian Njo K, Karim AB: Results of radiotherapy and vitamin $\mathrm{E}$ in the treatment of Peyronie's disease. Int J Radiat Oncol Biol Phys 1995;31:571.

48. Pinsolle J, Michelet V, Coustal B, et al: Treatment of ameloblastoma of the jaws. Arch Otolaryngol Head Neck Surg 1995;121:994.

49. Marcove RC, Sheth DS, Takemoto S, et al: The treatment of aneurysmal bone cyst. Clin Orthop 1995;311:157.

50. Kjaersgaard-Andersen P, Schmidt SA. Total hip arthroplasty. The role of antiinflammatory medications in the prevention of heterotopic ossification. Clin Orthop Relat Res 1991 Feb;(263):78-86

51. Alfthan O, Holsti LR: Prevention of gynecomastia by local roentgen irradiation in estrogen-treated prostatic carcinomas. Scand J Urol Nephrol 1969;3:183

52. Chou JL, Easley JD, Feldmeier JJ, et al. Effective radiotherapy in palliating mammalgia associated with gynecomastia after DES therapy. Int J Radiat Oncol Biol Phys 1998;15:749.

53. Scottish Cancer Trials Breast Group and ICRF Breast Unit, Guy's Hospital, London: Adjuvant ovarian ablation versus $\mathrm{CMF}$ chemotherapy in premenopausal women with pathological stage II breast carcinoma: The Scottish trial. Lancet 1993;341:1293.

54. Modry DL, Strober S, Hoppe RT, et al. Total lymphoid irradiation: Experimental models and clinical application in organ transplantation. Heart Transplant 1983;2:122 